\title{
Investigation of Electron Transfer-Based Photonic and Electro-Optic Materials and Devices.
}

\section{DOE Award No.:}

Recipient:

2. Project Title:

Project Director:

Principal Investigator:

\author{
DE-FG02-01ER45869
}

University of Montana-Missoula (UM) with subcontracts to Montana State University-Bozeman (MSU) and Mt Tech (Tech) of the University of Montana in Butte.

\section{Investigation of Electron Transfer-Based Photonic and Electro-Optic Materials and Devices.}

Jerry J. Bromenshenk

Lee Spangler

3. Date of Award Period Covered: September 28, 2003-December 28, 2007

Approved Budget per Year: Total from DOE was \$1,022,302.

On average, we budgeted $\$ 340,767$ for each year from DOE, with a 1:1 Match from State Sources. The project match slightly exceeded $(\sim 1 \%)$ the DOE Share.

4. Participating National Laboratories: Pacific Northwest National Laboratory

5. Abstract: Montana's state program began its sixth year in 2006. The project's research cluster focused on physical, chemical, and biological materials that exhibit unique electrontransfer properties. Our investigators have filed several patents and have also have established five spin-off businesses (3 MSU, $2 \mathrm{UM}$ ) and a research center (MT Tech). In addition, this project involved faculty and students at three campuses (MSU, UM, MT Tech) and has a number of under-represented students, including 10 women and 5 Native Americans. In 2006, there was an added emphasis on exporting seminars and speakers via the Internet from UM to Chief Dull Knife Community College, as well as work with the MT Department of Commerce to better educate our faculty regarding establishing small businesses, licensing and patent issues, and SBIR program opportunities.

\section{Accomplishments During the Reporting Period:}

\section{Management:}

Director:

Computer Specialist:

Co-Director:

Co-Director:
Jerry J. Bromenshenk, University of Montana-Missoula

Robert A. Seccomb, University of Montana-Missoula

Hugo Schmidt, Montana State University, MSU

David Hobbs, MT Tech, Butte 
Research Principal Investigator: Lee Spangler, MSU

Montana has management co-directors at each of the three campuses, which are 100-200 miles apart. These managers act as sources of information, provide assistance with DOE-related issues including points of contact and approval/letters of recommendation for applications such as the DOE Laboratory Partners programs. Each coordinator also provides onsite coordination of the research investigators at their respective campuses.

This project also had a lead research Technical/Principal Investigator, Dr. Lee Spangler, who specifically oversaw the science being conducted.

The state directors encourage investigators to include minority and other under-represented groups in their research. The outcome is obvious based on a high percentage of women and native American students who worked on these projects.

The state directors also work closely with the Montana University System Research VicePresidents to set research priorities and to identify and provide matching funds.

Four major activities of the State EPSCoR office in Missoula have been to:

1) provide audio/visual communications among the three campuses and to Chief Dull Knife College, a native American college in eastern MT that works with both UM and MSU. Initially, the DOE Access Grid was used. However, that system requires special equipment and training to use. During the last two years, the campuses were linked using more readily available commercial equipment from Polycom. This system is now in place to continue to support research coordination and distribute seminars among the campuses.

2) Continue to maintain the DOE DEARS reporting system, which has now been replaced by DOE's own system.

3) Work with the MT Department of Commerce and investigators to facilitate establishment of spin-off businesses resultant from federally funded research.

4) Work closely with groups working to increase the number of women and native Americans in science and mathematics, with an emphasis on hands on research.

\section{Research Teams by Co-PI:}

\section{Co-P.I. - E.H. Abbott}

The initial goals of this project were to develop methods to fabricate molecular wires based on polymeric platinum complexes. To this end we studied the polymerization which occurs when bis(oxalate) palatinate(II) anions are oxidized. We characterized the dimer, trimer, tertramer, and pentamer species containing two to five platinum atoms bound to one another in linear arrays ${ }^{1}$ and we showed that macroscopic wires were themselves polymers of the pentameric species. $^{2}$ Optical properties and thermodynamic formation constants were reported as well. Further studies involved cyanide and isocyanide complexes. The goal was to use functionalized isocyanides to attach the wires covalently to surfaces. New complexes were discovered and they have the potential for polymerization and wire formation. Careful control of the nature of the 
ligands leads to mixed ligand complexes that delicately balance the electrical properties of the central metal ion. ${ }^{3}$

During the course of this work we discovered that the polymeric platinum complexes we were preparing had unusual electrical properties. These complexes have impedance spectra which are essentially linear over a dynamic range of five or more orders of magnitude of frequency. This property enables the construction of fractional order control circuits and we demonstrated that they could provide temperature control without significant overshoot when the temperature was changed. ${ }^{4}$

Further work showed that the growth of molecular wires could be controlled so that wires could be fabricated so that they would grow through narrow channels and through the interstices of porous materials. Using electrolysis to oxidize the substrate material, we could use electrode placement and controlled voltage to grow the wires slowly and in the locations that we chose. Also, we showed that elaborate structures could be created by growing the wires through complex templates and we prepared wires as few as 19 atoms thick by growing them through nano pores. ${ }^{5}$

As the project concluded we were growing wires in microfabricated channels. Unsolved problems mainly involved making reliable electrical connections. Future work should be directed at growing wires of minimal diameter, presumably only as wide as a single complex constituent. Such wires would be attached to electrodes at both ends and the investigation of their electrical properties would be an important project.

\section{References}

${ }^{I}$ D. Sartori, S. K. Hurst, N. Wood, R. Larsen, and E. H. Abbott. Crystal structure, physical properties and Pt-195 NMR characterization of Pt(bipy)Br2. Chemical Crystallography (2005) 35995.

${ }^{2}$ B. J. Keller, S. K. Hurst, E. S. Peterson, L. H. Spangler and E. H. Abbott. Solution Equilibria Leading to the Formation Metal-metal Bonds in Partially Oxidized Bisoxaltoplatinate(II) Systems. Inor. Chim. Acta. Vol (2004) 357/3 853-858.

${ }^{3}$ P. J. Martellaro, S. K. Hurst, R. Larson, E. H. Abbott, and E. S. Peterson. Multifnuclear Nuclear Magnetic Resonance and X-ray Crystallographic Investigation of Some Mixed Ligand Alkylisocyanide Platinum(II) Complexes. Inorg. Chim. Acta. 358 (2005) 3377-83.

${ }^{4}$ S. K. Hurst, L. Spangler, E. H. Abbott, R. Larsen and E. S. Peterson. Preparation and Properties of Partially Oxidized N-methylisoquinolinium Bis(oxalate)platinate Nanowires. Inorg. Chim. Acta. (2004)1 358 173-176.

${ }^{5}$ B. M. Anderson, S. K. Hurst, L. Spangler, E. H. Abbott, P. Martellaro, P. J. Pinhero, and E. S. Peterson. The Investigations of the Macroscopic and Nanoscopic Physical Properties of the Partially Oxidized Polymers of Bisoxalatoplatinum(II) and Tetracyanoplatinum(II). J. Matl. Sci. (2006). 


\section{Co-P.I. - David Dickensheets}

Our group worked on two different classes of micro-engineered materials that will add to our technology base and lead to new useful devices. The first effort targets microstructured thin films for micro-electro-mechanical-systems, or MEMS devices. We are using micromolding techniques developed by MSU with DOE support to create and efficiently model periodic structures that strengthen micromechanical devices such as mirrors for fiber optic switches or endoscopic cameras. The second effort in collaboration with Dr. Ed Abbott is regarding nanowires made from platinum, which are grown in small micromachined channels that allow us to study their growth mechanism and electrical properties. Such wires could form the foundation for nano-electronic interconnects as well as novel optical materials.

A molded honeycomb structure provides a stiffening matrix for a micromirror designed for laser beam pointing control. Engineered MEMS materials such as this provide unique mechanical properties for a variety of applications, including miniaturized optical systems. Such systems are shrinking to satisfy the needs of long-haul communications on optical fiber, consumer products such as CD and DVD drives and digital cameras, and photonics systems for defense and national science and technology programs.

Our research has produced a novel micro-fabrication process and led us to a better understanding about how to model complex mechanical parts on a micro scale in order to accomplish informed engineering design of new devices. We have successfully demonstrated the use if this technology in a fiber optic switch and applied for a patent of our process and the micromirrors created with it. More recently we have studied these new latticed materials using analytical homogenization theory, finite element modeling and compared those results to experimental MEMS structures such as cantilever beams. The following summarizes some key results and accomplishments:

- We developed a fabrication process for molded Silicon Nitride thin film devices, and demonstrated how this process could be used to make very lightweight but stiff micromirrors. The mirrors were demonstrated in an optical switch application. These results were published in IEEE Photonics Letters.

- We studied bulk material properties resulting from variation in microstructure, for example square cells vs. hexagonal cells, and verified simulated performance with experimental structures. We presented these results at an international conference on optical MEMS in Oulu, Finland.

- Jeff Lutzenberger successfully defended his thesis on the topic of periodically stiffened thin film structures. He demonstrated that it is possible to model such structures using analytical homogenization theory which greatly simplifies analysis and makes practical engineering of such devices possible. A journal paper capturing his key results is in preparation.

The Platinum nanowire project has been described elsewhere in detail by co-PI Ed Abbott. Our involvement was the creation of micromachined substrates for more controlled growth of these nanowires. The following summarizes key accomplishments:

Undergraduate student Jon Shafer designed and built micromachined substrates for the platinum nanowire growth studies, using the MSU microfabrication facility. Several wire growth 
experiments were undertaken and the results presented at a regional conference by Jon and Chemistry undergraduate Nick Reif.

\section{Co-P.I. - Professor J. David Hobbs}

During the last 3 year, we have upgraded a 10-processor Linux cluster in the DOE sponsored materials modeling laboratory at Montana Tech to a 28-processor (64-bit AMD Opteron) with a Linpack benchmark of 57GFlops. Using the Linux cluster we are now better able to prepare large multiprocessor calculations to be run on massively parallel computer clusters at Pacific Northwest National Laboratory (PNNL) where we have established a collaboration (and been provided with 50,000 hours CPU time at the Molecular Science Computing Facility) with PNNL to calculate novel carbon-13 NMR shifts for bioactive metabolites isolated from phototropic organisms living in the extreme chemical environment of the Berkeley Mine Pit Lake. These and other computational efforts have employed four undergraduate students, including three women (two of whom are Native American minorities) in advanced molecular modeling studies of photo-optical and photocatalytic materials, as well as gaining valuable experience in HPC system administration. These systems have also supported computational efforts by faculty at UM/Missoula One graduate, Dan Cleary, who worked on EPSCoR projects for two years at Montana Tech, was accepted to a computational biomaterials Ph.D program at the California Institute of Technology in the fall of 2004, and now is completing an MD/Ph.D. program at Oregon Health Sciences centers that will have a significant computational neuro-science component. Another EPSCoR undergraduate student, Joe Henrich, is now a graduate student in material sciences at Ohio State. Both of these students were motivated to pursue advanced studies in materials and computational sciences through their research in our DOE supported projects. DOE support for cluster computing has resulted a significant support from Montana's Governor for further state investment in cyberinfrastructure. Currently Montana Tech has received $\$ 275 \mathrm{k}$ for statewide cyberinfrastructure planning and an additional $\$ 509 \mathrm{k}$ for establishing a HPC center at Montana Tech available to both private and university researchers, and also includes monies directed by the Office of the Commissioner of Higher Education to provide for HPC workforce development. Current projects in our laboratory include several undergraduate projects as well as planning for expanded HPC capabilities and staff (Summer, 2008).

\section{Co-P.I. - Lee H. Spangler}

The objective of this project is to design, synthesize, and characterize linked electron donoracceptor compounds exhibiting fast efficient forward photoinduced electron transfer and longlived charge separated states (CS). The lifetimes of CS states are sensitive to many factors including the relatively unexplored dependence on the flexibility of the linkage between the donor and acceptor. The triphenylamine group possesses good electron donating ability and in this study was covalently linked to $\mathrm{C}_{60}$ with a short, flexible linkage. One- and 2-arm versions (D1 and D2) of the dyad were synthesized. Photoinduced intramolecular electron transfer in benzonitrile was observed in these $\mathrm{C}_{60}$-donor dyads (DPAP- $\mathrm{C}_{60}$ ).

Excitation at $360 \mathrm{~nm}$ results in emission intensities of D1 and D2 that are quenched 35- and 9fold respectively, compared to emission from the reference compound DPAP. This indicates that the excited state of DPAP is quenched efficiently by the linked $\mathrm{C}_{60}$. The emission intensity of the 
single armed D1 is four times smaller than that of D2 at the same DPAP concentration. Further, excitation of the DPAP moiety with $400 \mathrm{~nm} 150$ ps pulses reveals a shortening of the

fluorescence lifetimes of D1 ( $\tau=9 \mathrm{ps})$ and D2 $\left(\tau_{1}=20 \mathrm{ps}, \tau_{2}=1.8 \mathrm{~ns}\right)$ relative to $\operatorname{DPAP}(\tau=1.8 \mathrm{~ns})$.

The decay mechanism of the CS state was investigated by collecting transient absorption spectra following nanosecond laser excitation at $532 \mathrm{~nm}$. The temporal decay profiles of both D1 and D2 show two components. The time constant of the fast component is about $330 \mathrm{~ns}$, while that of the slow component is about $1 \mathrm{~ms}$.

Dependence of the formation of the CS state on solvent was also investigated. In toluene, only absorption of the ${ }^{3} \mathrm{C}_{60}{ }^{*}$ moiety was present in the transient absorption spectrum. From the decay of the time profile, the lifetime of DPAP- ${ }^{3} \mathrm{C}_{60}{ }^{*}$ was evaluated to be $18 \mu \mathrm{s}$, which is close to that of $\mathrm{C}_{60}$ alone. This indicates that the intersystem crossing process from DPAP- ${ }^{1} \mathrm{C}_{60}{ }^{*}$ to DPAP${ }^{3} \mathrm{C}_{60}{ }^{*}$ is the predominant one with no charge separation in nonpolar solvents.

To our knowledge, the millisecond lifetime is the longest CS lifetime in solution ever reported for intramolecular charge recombination at room temperature in donor-acceptor dyad systems involving one-step electron transfer. Evolution of the CS band shape over a $300 \mathrm{~ns}$ timescale suggests conformational changes resulting in some solvent separation of the linked DPAP ${ }^{+}$and $\mathrm{C}_{60} 0^{-}$. This may lead a new synthetic strategy to attain long lifetime charge separation donoracceptor dyads by using flexible linkages and controlling the folding.

\section{Co-P.I. - Dr. Richard P. Donovan}

This program is directed at developing unique applications for artificial intelligence (AI) algorithms. The current project is specifically focused on the use of Artificial Neural Networks (ANNs) for calculating the material properties of advanced composite materials and classification of anomalous activities at regional airports. An ANN application was developed that dramatically reduces the cpu time required to calculate the material properties of advanced composite materials. In addition, ANN applications have been developed and deployed to detect and classify the activities of vehicles approaching the terminal at Bert Mooney Airport Authority (BMAA). In support of these efforts, DOE funding was utilized to deploy significant cyberinfrastructure consisting of a 28 processor cluster computer and a smart sensor network at BMAA.

ANNs have been utilized in voice recognition, pattern recognition, sensor networks, and other complex applications such as constitutive modeling. For example, ANNs have been used to determine constitutive relations for viscoelastic materials [Qingbin, et. al.] as well as aluminum alloys [Sen, et. al.]. Research has also shown that the global elastic constants of a composite material using the eigenvectors of experimental Lamb waves can be predicted [Yang]. The development of an ANN consists of establishing the underlying network topology, training the network with a set of known inputs and corresponding outputs, and validation against a set of known inputs and corresponding outputs. The validation set is not used in the training process. This approach to constitutive modeling was validated with applications to the Ideal Gas Law, control of talc processing and predicting the global properties of advanced composite materials.

The Ideal Gas Law is a constitutive law relating the four variables and one constant of the familiar: PV $=\mathrm{nRT}$. We use the ANN to solve for the output (target), which in this case is 
Temperature (T). The complete data set for 1 Mole of gas was calculated using the following data: Temperature $(\mathrm{T})=100^{\circ}-500^{\circ}$ Kelvin in increments of $10^{\circ}$; Volume $(\mathrm{V})=1-7.5$ meters $^{3}$ in increments of $0.5 ; \mathrm{R}($ Gas constant $)=8.315 \mathrm{Joules} /\left(\mathrm{mol}^{*} \mathrm{~K}\right)$; and $\mathrm{P}=\mathrm{nRT} / \mathrm{V}$. The final data set consists of 201 data points. The data was separated into training (80\%) and validation (20\%) sets. The training data are used to 'train' the network to adequately learn the known system. The test data are used to confirm that sufficient training occurred and that the ANN is able to predict the correct outcome (Temperature) using new data inputs. The network accurately predicted the temperature within $8^{\circ}$ Kelvin, which is less than $\pm 1 \%$ error.

ANNs were also used to model the processing of talc at the Luzenac America talc plant in Three Forks MT. The goal of this application is to model the plant (predict the current data set value(s)) and also predict how the plant processes are changing (the future data set value(s)). If this can be done it will prove that the network can predict the present state (constitutive law) and the future state (aid in the control of the system). The modified (changed to work with the ANN) control system could then use the predicted values from the ANN to make changes to the plant to keep the process from going unstable. In doing this the ANN will also be used to find the minimum energy state for the process to help control the process and minimize energy costs.

The ANNs have been able to learn and predict with reasonable error (less than 5 percent) the global outputs of the system. By creating new MNNs based off the SNNs design we have been able to achieve tighter accuracy than by training a single ANN to predict the system

DOE EPSCoR support was used to develop and deploy a sensor network at BMAA (Butte MT) in order to detect and classify anomalous vehicular traffic approaching the terminal curbside at BMAA. It consists of "weigh-in-motion" systems, video tracking/classification systems, ultra wide band (UWB) radar tracking.

To support future development of high performance computing and sensor networks the Montana Institute for Simulation Technologies (MIST) has been established with funding from the Montana State government. The fundamental goal of MIST is to build upon these programs initiated with DOE EPSCoR funding to create sensor network test beds and a High Performance Computing and Visualization center. These testbeds and the HPC center will be connected via Access Grid Node technology to form a statewide cyber infrastructure system.

The sensor network test beds will be utilized to develop accurate classifications systems of anomalous behavior at small regional airports such as BMAA. This work will require significant computing power (HPC) to accurately and quickly train ANNs to perform a variety of tasks within the sensor network. The HPC and Visualization Center will be utilized for development of computational material science, natural resource modeling and complex system design.

\section{References}

Nguyen, Hanh. H., Christine W. Chan. (April 2004). "Multiple neural networks for a long term time series forecast." Neural Computing \& Applications, v13 n1, 90-98.

Qingbin, Liu, Et al. (1996) "Acquiring the constitutive relationship for a thermal viscoplastic material using an artificial neural network." Materials Processing Technology. 206-210. 
Sen, Senjeev.,Janet M. Twomey. (2002). "Parameter estimation using a connectionist constitutive model for aluminum 7075 alloy.” Smart Engineering System Design. v12 889-894.

Wolpert, D. H. (1992). Stacked generalization. Neural Networks, 5(2) 241-259

Yang, Jing. Jian-Chun Cheng. (2001). “A New Inverse Method of Elastic Constants for a Fibre Reinforced Composite Plate from Laser-Based Ultrasonic Lamb Waves.” Chinese Physics Letters. V18 n12 1620-1623.

\section{Co-P.I. - Edward Rosenberg}

The primary goals of this project are to develop a series of transition metal based electroactive biomarkers and structural probes for applications in the study of the structure and dynamics of DNA and proteins. The PI and his group focus on the synthesis and characterization of these probes and on the evaluation of their photophysical and electrochemical properties. Once these properties are well defined collaborations with structural biologists are sought out in order to test the applicability of the particular probe to problems in structural biology. To date three such collaborations have been established with biochemists at UM and MSU.

During this funding period work proceeded on developing metal cluster complexes that were both luminescent and electron transfer active. In particular, a thorough study of a 2-amino anthracene complex was completed. The reactions of 2-amino-anthracene with $\left[\mathrm{Os}_{3}(\mathrm{CO})_{10}\left(\mathrm{CH}_{3} \mathrm{CN}\right)_{2}\right]$ have been studied and the products structurally characterized by spectroscopic, X-ray diffraction and electrochemical techniques. At room temperature in $\mathrm{CH}_{2} \mathrm{Cl}_{2}$ two major, isomeric products are obtained $\left[\mathrm{Os}_{3}(\mathrm{CO})_{10}\left(\mu-\eta^{2}-(\mathrm{N}-\mathrm{C} 3)-\mathrm{NH}_{2} \mathrm{C}_{14} \mathrm{H}_{8}\right)(\mu-\mathrm{H})\right](\mathbf{1}, 14 \%)$ and $\left[\mathrm{Os}_{3}(\mathrm{CO})_{10}\left(\mu-\eta^{2}-(\mathrm{N}-\mathrm{C} 1)-\mathrm{NH}_{2} \mathrm{C}_{14} \mathrm{H}_{8}\right)(\mu-\mathrm{H})\right](2,35 \%)$ along with a trace amount of the dihydrido complex $\left[\mathrm{Os}_{3}(\mathrm{CO})_{9}\left(\mu-\eta^{2}-(\mathrm{N}-\mathrm{C} 3)-\mathrm{NHC}_{14} \mathrm{H}_{8}\right)(\mu-\mathrm{H})_{2}\right]$ (3). In refluxing tetrahydrofuran only complexes 1 and 3 are obtained in 24 and 28\% respectively. Separate experiments show that complex $\mathbf{2}$ slowly converts to $\mathbf{1}$ and that complex $\mathbf{2}$ is stereochemically non-rigid, exhibiting edge to edge hydride migration while $\mathbf{1}$ is stereochemically rigid. Complex $\mathbf{3}$ is also stereochemically non-rigid showing site exchange process of the magnetically nonequivalent hydrides typical for trinuclear dihydrides. Interestingly, $\mathbf{1}$ decarbonylates cleanly to the electronically unsaturated $46 \mathrm{e}^{-}$cluster $\left[\mathrm{Os}_{3}(\mathrm{CO})_{9}\left(\mu_{3}-\eta^{2}-(\mathrm{N}-\mathrm{C} 3)-\mathrm{NH}_{2} \mathrm{C}_{10} \mathrm{H}_{8}\right)(\mu-\mathrm{H})\right](4,68 \%)$ in refluxing cyclohexane, while photolysis of $\mathbf{1}$ in $\mathrm{CH}_{2} \mathrm{Cl}_{2}$ yields only a small amount of 3 along with considerable decomposition. The differences in the photochemical and thermal behavior of 1 and the dependence of the product distribution on solvent are briefly discussed. Complexes 13 all show irreversible $1 \mathrm{e}^{-}$reductions at $\sim 1.6 \mathrm{~V}$ while 4 shows a nicely reversible $1 \mathrm{e}^{-}$wave at $0.73 \mathrm{~V}$ and a quasi-reversible second $1 \mathrm{e}^{-}$at-1.20 V. All four compounds are luminescent with compounds 1-3 showing emissions that can be assigned to radiative decay from the anthracene ligand while 4 emits at $740 \mathrm{~nm}$ when excited at its longer wavelength absorption maxima.

We also completed a study of the sulfur containing aromatic heterocycle thianthrene with the goal of understanding the influence of a different heteroatom on the photophysical and electrochemical properties of the corresponding triosmium cluster. Reaction of $\left[\mathrm{Os}_{3}(\mathrm{CO})_{10}\left(\mathrm{CH}_{3} \mathrm{CN}\right)_{2}\right]$ with thianthrene at $80{ }^{\circ} \mathrm{C}$ leads to the nonacarbonyl dihydride compound $\left[\mathrm{Os}_{3}(\mathrm{CO})_{9}\left(\mu-3,4-\eta^{2}-\mathrm{C}_{12} \mathrm{H}_{6} \mathrm{~S}_{2}\right)(\mu-\mathrm{H})_{2}\right]$ (1) and the 46-electron monohydride compound $\left[\mathrm{Os}_{3}(\mathrm{CO})_{9}\left(\mu_{3}-\eta^{2}-\mathrm{C}_{12} \mathrm{H}_{7} \mathrm{~S}_{2}\right)(\mu-\mathrm{H})\right](2)$. Compound 2 reacts reversibly with $\mathrm{CO}$ to give the $\mathrm{CO}$ 
adduct $\left[\mathrm{Os}_{3}(\mathrm{CO})_{10}\left(\mu-\eta^{2}-\mathrm{C}_{12} \mathrm{H}_{7} \mathrm{~S}_{2}\right)(\mu-\mathrm{H})\right]$ (3) whereas with $\mathrm{PPh}_{3}$ it gives the addition product $\left.\left[\mathrm{Os}_{3}(\mathrm{CO})_{9}\right)\left(\mathrm{PPh}_{3}\right)\left(\mu-\eta^{2}-\mathrm{C}_{12} \mathrm{H}_{7} \mathrm{~S}_{2}\right)(\mu-\mathrm{H})\right]$ (4) as well as the substitution product 1,2$\left[\mathrm{Os}_{3}(\mathrm{CO})_{10}\left(\left(\mathrm{PPh}_{3}\right)_{2}\right]\right.$ (5). Compound 2 represents a unique example of an electron-deficient triosmium cluster in which the thianthrene ring is bound to cluster by coordination of the sulfur lone pair and a three-center-two-electron bond with the $\mathrm{C}(2)$ carbon which bridges the same edge of the triangle as the hydride. Electrochemical and DFT studies which elucidate the electronic properties of 2 were reported.

Finally, as a result of a new collaboration with colleague and biophysicist J. B. A. Ross we have started a study of the synthesis, photophysical properties of a new class of mononuclear ruthenium complexes of general formula $\mathrm{Ru}(\mathrm{LL})(\mathrm{LL}$ ')COX (LL=bipyridyl, phenanthroline, LL' =two phosphine ligands or a chelating phosphine, $\mathrm{X}=\mathrm{H}$, or trifluoroacetate). The complexes were designed to have higher quantum yields, longer lifetimes, larger stokes shifts and high anisotropies of emission than previously reported probes of this type. To date, 10 complexes have been synthesized and the desired properties have been realized. Two of these have been conjugated to cholesterol and to lipids for use in membrane studies. These studies are on-going and will form the basis of an NSF grant that will be submitted this summer. This new project is by far the most promising of all the work done in this last funding period.

\section{Co-P.I. - David J. Singel}

This objective of this program is to advance the use of macromolecular assemblies as templates that enable the production of organized arrays of chemical substituents on the template surfaces. Such ordered arrays have numerous applications, including probing and tailoring multivalent ligand-receptor coupling and, similarly, probing and tailoring structures of electron donoracceptor couples.

We initially focused on the use of globular, PAMAM (polyamido-amino) starburst dendrimers of various sizes (generation number) as templates upon which to synthesize organized arrays of functionalities. We developed new electron spin resonance and mass spectrometry methods to characterize the chemistry of heterogeneous functionalization with molecular groups, e.g., nitroxyl spin-label molecular probes, single-ring aromatics, and small carbohydrates. These structurally-characterized, functionalized templates are presently being applied as analytical probes cell-cell interactions [1].

Our work provided the first characterization of the heterogeneous functionalization of such complex molecules. We introduced a novel method of analyzing the line-widths of peaks in MALDI-MS (matrix-assisted laser-desorption mass spectrometry) to analyze the manner in which the distribution of loading percentages (i.e., the degree of functionalization) varies with the average loading [2]. We found that a simple Poisson distribution loading model adequately summarizes the observed MALDI-spectra.

We also developed a new method to analyze the multi-spin EPR (electron paramagnetic resonance) spectra of heterogeneously spin-labeled dendrimers [2,3]. The method involves analysis of trends in spin-spin dipolar broadening as a function of the degree of spin-probe loading. Our analysis demonstrated that the spatial distribution of functional groups on partially loaded PAMAM dendrimers is random. We further discovered that the effective dimensionality of the loaded template is two-dimensional in smaller generations, but three-dimensional in larger 
dendrimers (generation 4 and higher). The theoretical prediction of effective three-dimensional behavior at all generation numbers is not compatible with our findings [4]; the origin of the discrepancy is not yet known. In ongoing work, we are, through synthetic strategies, incorporating order into the array functional groups, then using spectroscopic methods to elucidate the time-scale over which the order persists [5].

The structural flexibility of the PAMA dendrimers presents a serious limitation on the control of the spatial distribution of attached groups. We therefore initiated experiments aimed at using the more rigid templates afforded by multi-subunit protein cage assemblies. While our initial interest was chemical functionalization in the interior of the protein cages, specifically with the goal of controlled synthesis of mono-disperse metal and metal oxide nanoparticles [6], we also realized that the exterior of these cages provides an attractive template, like a dendrimer, for bread-boarding molecular circuitry. The more rigid protein assembly, however, allows far greater control of the distribution of attached functional groups. Through site-directed mutagenesis they are amenable to functionalization at selected positions, with distinctive spatial distributions of attached groups [7]. In addition, some cages undergo structural transitions, which can be gated, for example, by changes in $\mathrm{pH}$, or metal ion concentrations. Such gated phase transitions enable environment-responsive alteration of the spatial distribution of the attached groups, and, thus, alteration of the functional properties of the molecular circuit.

A protein cage system that exhibits such a gated response is CCMV (cowpea chlorotic mottle virus) [8]. CCMV is a cage composed of 180 sequence identical protein subunits that make an icosahedron constituted of trimers of the subunits. It has a diameter of $28 \mathrm{~nm}$ in the "closed" form depicted, but swells to $35 \mathrm{~nm}$ diameter in its "open" form that is induced, for example, at elevated $\mathrm{pH}[8,9]$.

We are using site-directed spin labeling approaches [10] to probe the mechanistic nature of this transition. The major issue to be resolved, which is also of current theoretical interest [9], is whether the large structural change occurs in a cooperative, all-at-once fashion as suggested theoretically, or, instead, steps through a series of (not necessarily well-defined) intermediate structures. The former situation is ideal for on/off response in sensor application. By scrutiny of the open and closed structures we have identified which sequence positions can be labeled for maximal changes in the distance among attached functional groups [7]. To test for cooperativity, we spin label at the selected sites, then follow changes in the EPR spectra vs. pH in series of samples labeled such swelling-sensitive positions. For CCMV cages with spin-labels attached at the residue positions 59 and 108 (wild-type), we found that the EPR spectra at any $\mathrm{pH}$ is expressible as linear combination of two "basis" spectra observed at the extreme high and low $\mathrm{pH}$ values surveyed. This two-state behavior is characteristic of a cooperative, gated swelling process [7].

References

1. E.K. Woller, E.D. Walter, J.R. Morgan, D.J. Singel and M.J. Cloninger. Altering the strength of lectin binding interactions and controlling the amount of lectin clustering using mannose/hydroxyl-functionalized dendrimers. Journal of the American Chemical Society (2003) 125 8820-8826; L.E. Samuelson, K.B. Sebby, E.D. Walter, D.J. Singel and M.J. 
Cloninger. EPR and Affinity Studies of Mannose-TEMPO Functionalized PAMAM Dendrimers. Organic \& Biomolecular Chemistry (2004) 2 3075-3079.

2. E.D. Walter, K.B. Sebby, R.J. Usselman, D.J. Singel and M.J. Cloninger. Characterization of heterogeneously functionalized dendrimers by mass spectrometry and EPR spectroscopy. Journal of Physical Chemistry (2005) B 109 21532-21538.

3. K.B. Sebby, Ph.D. thesis, Montana State University (2007); manuscript in preparation.

4. M. Ballauf, and C.N. Likos. Dendrimers in solution: insight from theory and simulation. Angew. Chem. Int. Ed. (2004) 43, 2998-3020.

5. H.-J. Han, K.B. Sebby, D.J. Singel, and M.J. Cloninger. EPR Characterization of Heterogeneously-functionalized Dendrimers. Macromolecules (2007) 40 3030-3033.

6. Electron Magnetic Resonance of Iron Oxide Nanoparticles Mineralized in Protein Cages. R.J. Usselman, M. Klem, M. Allen, E.D. Walter, K. Gilmore, T. Douglas, M. Young, Y. Idzerda and D.J. Singel. Journal of Applied Physics 97 (2005): Art. No. 10M523 Part 3.

7. R. J. Usselman, Ph.D. thesis, Montana State University 2006; manuscript in preparation.

8. J.A. Speir, S. Munshi, G. Wang, T.S. Baker, J.E. Johnson. Structures of the native and swollen forms of cowpea chlorotic mottle virus determined by X-ray crystallography and cryo-electron microscopy. Structure (1995) 15;3(1):63-78; H. Liu H, C. Qu C, J.E. Johnson, D.A. Case. Pseudo-atomic models of swollen CCMV from cryo-electron microscopy data. J. Struct. Biol. (2003) 142(3):356-63.

9. F. Tama, C.L Brooks. CL 3rd. The mechanism and pathway of $\mathrm{pH}$ induced swelling in cowpea chlorotic mottle virus. J. Mol. Biol. (2002) 3;318(3):733-47.

10. W.L. Hubbell, D.S. Cafiso, C. Altenbach C. Identifying conformational changes with sitedirected spin labeling. Nat. Struct. Biol. (2000) 7(9):735-9.

\section{Co-P.I. - Aleksander Rebane and Co-P.I. - Charles Spangler}

The project was directed at the development of new nonlinear-optical materials for emerging applications such as multi-photon fluorescence imaging, nonlinear optical power switching, high-density optical data storage, and photodynamic therapy. These applications depend critically on efficient multi-photon absorbing materials with various functionality properties. In our project we designed, synthesized (synthesis performed by Ch. Spangler group) and characterized new functionalized conjugated organic compounds, such as branched PPVdendrimers and tetrapyrroles with greatly increased cross-section of simultaneous absorption two photons (2PA) as well as three photons (3PA). As a result of this project, we have achieved: (a) record large multi-photon cross sections; (b) improved understanding of underlying physical effects such as quantum interference; (c) established practical structure-property relationships for optimizing NLO properties of organic compounds; (d) developed improved methodology for 
measuring two-photon and three-photon absorption spectra in visible and near-IR range of laser wavelengths. The following shows some scientific highlights:

- We used wavelength tunable femtosecond pulses to measure the intrinsic 2PA and 3PA cross sections and spectra in two series of $\pi$-conjugated dendrimers built of identical 4,4 'bis(diphenylamino) stilbene (BDPAS) and 4,4'-bis(diphenylamino) distyrylbenzene (BDPADSB) repeat units. Record large 2PA cross sections, $\sigma_{2}=10^{-46} \mathrm{~cm}^{4} \mathrm{~s}$ are obtained for the largest second-generation BDPAS-based dendrimer, as well as zeroth-generation 4-arm BDPADSB-based dendrimer. In both series, maximum 2PA cross section increases nonlinearly with the number of $\pi$-electrons, whereas for higher generations this dependence turns to linear one. 3PA cross section also increases nonlinearly with the size of the system in the series of BDPAS-based molecules, amounting a record large value, $\sigma_{3}=10^{-79} \mathrm{~cm}^{6} \mathrm{~s}^{2}$, for the largest, second-generation dendrimer. We interpret these results in terms of direct inter-branch conjugation, which facilitates cooperative enhancement of the nonlinear-optical response. We propose a simple model which allows us to determine the effective size of coherent domains (extent of conjugation), which, in turn, determines the optimum dendrimer size for most efficient nonlinear response [2].

- We demonstrate, for the first time, high contrast quantum interference between onephoton and three-photon absorption pathways in an organic solid at room temperature. Illumination of a thin polymer film activated with fluorescing dendrimer chromophores of large three photon absorption cross section with two simultaneous femtosecond pulses at near-IR frequency $\omega$ and its third harmonic UV frequency $3 \omega$ results in a spatial interference fringe pattern observable by eye $[2,3]$.

- We study, for the first time, both theoretically and experimentally the requirements imposed on organic photochromes for 2PA terabyte volumetric optical data storage. We present a quantitative model of signal-to-noise ratio (SNR) and signal-to-background ratio (SBR) when writing of data bits is performed by means of 2PA-induced photochromic switching, and reading out is performed by 2PA-induced fluorescence [4].

- We study, for the first time, near-IR two-photon absorption (2PA) spectra of nonsymmetric push-pull metal-free phthalocyanines, which are present in solution at room temperature as a mixture of two spectrally non-equivalent tautomers T1 and T2. Large 2PA cross sections, $\sigma_{2}=(1-3) \times 10^{3} \mathrm{GM}$ are obtained in the excitation wavelength region $\lambda_{\text {ex }}=815-850 \mathrm{~nm}$ and are explained by (1) new CT state appearing in onephoton absorption (1PA) spectrum of these compounds at 420 - $430 \mathrm{~nm}$ and (2) strong resonance enhancement within quasi-three-level system when the Q-state(s) serve as the real intermediate state(s). In Q-region, $\lambda_{\mathrm{ex}}=1100-1500 \mathrm{~nm}, 2 \mathrm{PA}$ and 1PA transitions coincide and the 2PA strength of any pure electronic or vibronic band is quantitatively described in terms of two-level approximation [5].

\section{Co-P.I. - V. Hugo Schmidt}

Our work is related to electron transfer in a conductive polymer and a photostrictive material. Piezoelectric polymer sheets have metal electrodes that stiffen the sheet and decrease its 
response in actuator and sensor applications. We developed methods for applying electrodes of conducting polymer poly(ethylene dioxythiophene) (PEDOT-PSS) to sheets of piezoelectric poly(vinylidene fluoride) (PVDF). PEDOT-PSS electrodes have higher resistance than metal electrodes. We calculated $\mathrm{V}$ and $\mathrm{i}$ vs. position on the electrodes of a PVDF sheet. From the response $v s$. frequency plot, we found electrode thickness neeed for various applications. We tested bimorphs of two electroded sheets glued together to give a bending response. We constructed actuators made of two bimorphs, and got better response than for similar actuators constructed from sheets with metal electrodes. Our novel "bellows" actuator design has a deflection/volt ratio of $0.0164 \mathrm{~mm} / \mathrm{V}$, over 5 times better than for similar-size piezoelectric polymer actuators.

A difficulty with piezoelectric polymer actuators is viscoelastic creep, which causes position change if a given voltage is applied over a long time period, and causes nonrepeatability of a given desired displacement when a given voltage is applied.

The photostrictive work investigates dielectric and photovoltaic behaviors in $\mathrm{Pb}\left(\mathrm{Mg}_{1 / 3} \mathrm{Nb}_{2 / 3}\right)_{0.64} \mathrm{Ti}_{0.36} \mathrm{O}_{3}\left(\mathrm{PMNT35} \%\right.$ ) single crystal doped with 0.5 mole $\% \mathrm{WO}_{3}$.

The photovoltaic response depends on sample thickness, illumination wavelength, and prior poling. The thinner sample has higher photovoltage/thickness but lower photovoltage. The photovoltage is higher for $406 \mathrm{~nm}$ than for $488 \mathrm{~nm}$, because $406 \mathrm{~nm}$ photons are absorbed more effectively than the $488 \mathrm{~nm}$ light. The photovoltage is higher in the poled samples, perhaps because the photoelectron range is different in opposite directions because of the asymmetry of the poled crystal structure. The poled samples with prior polings at $E=5$ and $10 \mathrm{kV} / \mathrm{cm}$ exhibit similar photovoltaic responses, probably because the structural asymmetry is already almost saturated for $5 \mathrm{kV} / \mathrm{cm}$ poling. The relation of photovoltage and light intensity under nearultraviolet $(\lambda=406 \mathrm{~nm})$ illumination for the poled samples can be expressed by an exponential equation. The solid line is the fitting of the equation, $E_{p h}=5.7 \times 10^{-7}\left(I_{o p}\right)^{2.5}$, for the poled samples under $\lambda=406 \mathrm{~nm}$ illumination. A remaining challenge is to increase the photovoltage to the level needed to produce a strong piezoelectric response resulting in a useful displacement. Optical transmission reveals that the cut-off wavelength is near $400 \mathrm{~nm}$ and indicates a minimum electronic energy gap of $\sim 3.0 \mathrm{eV}$.

\section{Co-P.I. Michele McGuirl}

The specific aim of this project is to elucidate the nature of long range electron transfer (ET) in proteins, including possible multi-step tunneling via amino acid radicals and the effects of protein immobilization on the proton transfer (PT) step that accompanies biological ET. We proposed to pursue measuring ET rates via electrochemistry, in mutants of azurin in which a Trp or Tyr has been introduced at one of several specified positions in the structure. We substituted Trp or Tyr analogs (non-natural amino acids) in order to vary the redox potential of the aromatic residue at that position.

Significant Findings/Events/accomplishments

Using the grant funding, we have: 
- Prepared, purified, and characterized most of the planned azurin mutants. These include mutants that contain surface Cys residues for coupling to a gold electrode surface via dithioalkyl self assembled monolayers.

- Worked with techniques of incorporating Trp analogs into proteins, at levels that reached 50 $-95 \%$.

- Achieved $20 \%$ incorporation of fluoro-Tyr into proteins.

- Mastered the technique of forming self-assembled monolayers on gold electrode surfaces and measured the reduction potential of several metalloproteins as a control experiment.

- Measured the reduction potentials of Trp, Tyr, and analog-containing azurin proteins via direct electrochemistry

- Sent protein to Dr, Brian Crane for crystallographic structural studies and in-crystal ET studies

There was one notable barrier. The Tyr analog incorporation level was quite low and the expression yield is also much lower than expected. We tried a different vector and host strain but did not improve the yield.

The protein mutation, expression, purification, and characterization work was done by two talented female high schools students and a half-time technician. The PI and postdoc handled the electrochemistry.

The potentials of Trp and Tyr at position 28 (solvent exposed site) were measured. For Trp,t he Cys label had to be moved from position 27 to 25 . The signal from the K27C/Q28W mutant was broad and had multiple peaks, which we attributed to the Trp entering the SAM layer. The Trp potential was about $100 \mathrm{mV}$ higher than the Tyr potential, as expected for a solvent exposed site, and showed the expected change of $\sim-60 \mathrm{mV}$ per unit increase in $\mathrm{pH}$. At position 108 (partially exposed), the Trp potential was $\sim 100 \mathrm{mV}$ lower than Tyr. Interestingly, the potential of 5hydroxyTrp, which is $\sim 500 \mathrm{mV}$ lower than Trp when free in solution, was only $70 \mathrm{mV}$ lower than that of Trp when incorporated at 108. The protein environment was clearly modulating the potential of the residue at 108 . Moreover, none of the mutants showed much change with $\mathrm{pH}$, which we attribute to the lack of proton release to bulk solvent on the timescale of the electrochemical detection.

The X-band EPR spectrum of K28Y is much more rhombic than that observed for other previously reported protein-derived Tyr radicals. The high field W-band EPR studies should help to understand why this is so.

\section{Papers and Patents in which DOE Support is Acknowledged:}

C. Garino, S. Ghiani, R. Gobetto, C. Nervi L. Salassa, G. Croce, M. Milanesio, E.Rosenberg, J. B. A. Ross. "Tricarbonylchlororhenium (I) carboxaldimine derivatives: synthesis, structure and NMR characterization of $Z$ and $E$ isomers," Eur. Inorg. Chem. (2006) 14, 2885.

S. E. Kabir, M. A. Mottalieb, G. M. G. Hossain, E. Nordlander, E. Rosenberg. Reactions of ( $\mu-$ $\mathrm{H}) \mathrm{Os}_{3}(\mathrm{CO})_{10}(\mathrm{OMe})$ and of $(\mu-\mathrm{H}) \mathrm{Os}_{3}(\mathrm{CO})_{9}(\mathrm{OMe})(\mathrm{MeCN})$ with dppm, dppe, dppp and $\mathrm{PPh}_{2} \mathrm{H}$," Polyhedron (2006) 25, 95. 
S. E. Kabir, M. S. Saha, D. A. Tocher, G. M. G. Hossain, E. Rosenberg. "Triosmium Clusters Containing dppm and EPh,“ J .Organometal. Chem. (2006) 691, 97.

M. Hughes and E. Rosenberg. "Characterization and Applications of Poly-Acetate Modified Silica Polyamine Composites,” Sep. Sci. and Tech. 42 (2007) 261.

E. Rosenberg, C. Hart, M. Hughes, Raj Kailasam, J. Allen, J. Wood, B. Cross. “ Performance Improvement through Structural Design and Comparison with Polystyrene Resins of Silica Polyamine Composites," Proceedings of the $67^{\text {th }}$ International Water Conference (2007) IWC 06-34.

A. Albertino, C. Garino, S. Ghiani, R. Gobetto, C. Nervi, L. Salassa, E. Rosenberg, G. Viscardi, R. Buscaino, G. Croce, M. Milanesio, A. Sharmin. "Photophysical Properties and Computational Investigations of Tricarbonylrhenium(I)[2-(4-methylpyridin-2-yl)benzo-X-azole]L and Tricarbonylrhenium(I)[4-methyl-2-(1-methyl-1 $H$-benzo[ $d]$-X-azol-2-yl)quinoline]L derivatives $\left(\mathrm{X}=\tilde{\mathrm{N}} \mathrm{CH}_{3}, \quad \mathrm{O}\right.$, or $\mathrm{S} ; \mathrm{L}=\mathrm{Cl}$, pyridine), J. Organometal Chem 692 .(2007) 1377.

A. Sharmin, A. Minazzo , L. Salassa,' E. Rosenberg, J. B. A. Ross, S. E. Kabir, K. I. Hardcastle. "Synthesis, Structure, Photophysical and Electrochemical Behavior of 2-Amino-Anthracene Triosmium Clusters,” Inorg. Chim. Acta. 2008, 361, 1624.

T. J. Bandosz, M. Seredych, J. Allen ${ }^{2}$, J. Wood, and E. Rosenberg. "Silica-polyamine based carbon composite adsorbents as media for effective hydrogen sulfide adsorption/oxidation," Chem. of Materials 2007 19, 2500.

Claudio Garino, Simona Ghiani, Roberto Gobetto Carlo Nervi, Luca Salassa,Edward Rosenberg, J. B. Alexander Ross Xi Chu, Kenneth I. Hardcastle, Cristiana Sabatini. "Spectroscopic and Computational Studies of a $\mathrm{Ru}(\mathrm{II})$ Terpyridine Complex: The Importance of Weak Intermolecular Forces to Photophysical Properties. Inorg. Chem.. 2007 46, 8752.

Arun K. Raha, Mohammad R. Hassan, Shariff E. Kabir, Md. Manzurul Karim,Brian K. Nicholson, Ayesha Sharmin, ${ }^{3}$ Luca Salassa ${ }^{3}$ Edward Rosenberg.' "An Electron-Deficient Triosmium Cluster Containing the Thianthrene Ligand: Synthesis, Structure and Reactivity of $\left[\mathrm{Os}_{3}(\mathrm{CO})_{9}\left(\mu_{3}-\eta^{2}-\mathrm{C}_{12} \mathrm{H}_{7} \mathrm{~S}_{2}\right)(\mu-\mathrm{H})\right] ”$ J. Cluster Science 200819 (1).

Chi-Shun Tu, F.-T. Wang, R. R. Chien, V. H. Schmidt, T.-M. Hung, and C.-T. Tseng. "Dielectric and photovoltaic phenomena in tungsten doped $\mathrm{Pb}\left(\mathrm{Mg}_{1 / 3} \mathrm{Nb}_{2 / 3}\right)_{1-\mathrm{x}} \mathrm{Ti}_{\mathrm{x}} \mathrm{O}_{3}$ crystal," Applied Physics Letters 88, 032902/1-3 (2006).

V. Hugo Schmidt, Joseph Polasik, Laura Lediaev, and Jil Hallenberg. "Actuators Based on PVDF Sheets with Flexible PEDOT Polymer Electrodes," Proceedings of $12^{\text {th }}$ international symposium on Electrets, pp. 378-381, Salvador, Bahia, Brazil, September 11-14, 2005. 
V. Hugo Schmidt, Laura Lediaev, Joseph Polasik, and Jil Hallenberg. "Piezoelectric Actuators Employing PVDF Coated with Flexible PEDOT-PSS Polymer Electrodes," IEEE Transactions on Dielectrics and Electrical Insulation 13(5), 1140-1148 (2006).

Joseph T. Polasik, and V. Hugo Schmidt "Conductive Polymer PEDOT/PSS Electrodes on the Piezoelectric Polymer PVDF,". Proc. SPIE vol. 5759, pp. 114-120, Smart Structures and Materials 2005: Electroactive Polymer Actuators and Devices (EAPAD); Yoseph Bar-Cohen; Ed. May 2005.

Laura M. Lediaev and V. H. Schmidt. "Modeling PVDF Actuators with Conducting Polymer Electrodes," Proc. SPIE vol. 5759, pp. 470-478, Smart Structures and Materials 2005:

Electroactive Polymer Actuators and Devices (EAPAD); Yoseph Bar-Cohen; Ed. May 2005.

A. M. Vinogradov, V. H. Schmidt, G. F. Tuthill, and G. W. Bohannan. Mechanics. "Damping and electromechanical energy losses in the piezoelectric polymer PVDF," of Materials 36, pp. 10071016 (2004).

Jill Irene Lorenz- Hallenberg. "Application of Poly(3,4-Ethylenedioxythiophene)-Poly(Styrene Sulfonate) to Poly(Vinylidene Fluoride) as a Replacement for Traditional Electrodes," M.S. Thesis, Montana State University (August 2003).

A. Vinogradov, V. H. Schmidt, G. Tuthill, G. Bohannan. "Damping and electromechanical energy losses in the piezoelectric polymer PVDF." Mechanics of Materials 36 (2004) 10071016.

B. Jeffrey Lutzenberger, David L. Dickensheets and Todd J. Kaiser, "Large Area Molded Silicon Nitride Torsion Mirrors for Optical Switching," IEEE Photonics Technology Letters, 15 (10), pp 1407-1409, October, 2003.

B. Jeffrey Lutzenberger and David L. Dickensheets, "Fabrication and Modelling of Stiffened Thin Films," (in preparation for IEEE J. Microelectromechanical Systems).

B. Jeffry Lutzenberger, David L. Dickensheets and Phillip A. Himmer, "Periodic rib-reinforced silicon nitride scan mirrors," 2005 IEEE/LEOS International Conference on Optical MEMS, Oulu, Finland, pp 133-134, August 1-4, 2005.

David L. Dickensheets, Angela M. Kimmel. "MOEMS Torsion Mirror Addressed Variable Optical Delay," 2004 IEEE/LEOS International Conference on Optical MEMS, Takamatsu, Kagawa, Japan, pp 34-35, August 22-26, 2004.

Jon Shafer, Stephanie Hurst, Ed Abbott, Lee Spangler, Nick Reif, David Dickensheets, "Micromachined Substrates for Platinum Wire Growth," Optical Science and Laser Technology Conference, Montana State University, September 18-19, 2006. 
Jeffry Lutzenberger and D. L. Dickensheets, "Stiffening Thin Film MEMS with Periodic MicroStructures," poster presented at the 2003 Optical Science and Laser Technology Conference, Montana State University, September 19-20, 2003.

Jeff Lutzenberger (Ph.D. 2006), "Analysis And Design Of MEMS Scan Mirrors Using Periodically Stiffened Silicon Nitride"

A. Rebane, N. Christensson, M. Drobizhev, Y. Stepanenko, C.W. Spangler. "Quantum interference between multi photon absorption pathways in organic solid." Journal of Luminescence, (2007) 02.045.

M. Drobizhev, A. Rebane, Z. Suo, C.W. Spangler. "One-, two- and three-photon spectroscopy of $\pi$-conjugated dendrimers: cooperative enhancement and coherent domains." Journal of Luminescence 111 (2005) 291-305.

N. S. Makarov, A. Rebane, M. Drobizhev, H. Wolleb, and H. Spahni. "Optimizing two-photon absorption for volumetric optical data storage." J. Opt. Soc. Am. B/Vol. 24, No. 8/August 2007.

Mikhail Drobizhev, Nikolay S. Makarov, Aleksander Rebane, Gema de la Torre, and Tomas Torres. "Strong Two-Photon Absorption in Push-Pull Phthalocyanines: Role of Resonance Enhancement and Permanent Dipole Moment Change upon Excitation." J. Phys. Chem. C 2008, 112, 848-859.

Aleksander Rebane, Niklas Christensson, Mikhail Drobizhev, Yuriy Stepanenko, Charles W. Spangler. "Quantum interference in organic solid." 8 August 2005 / Vol. 13, No. 16 / OPTICS EXPRESS 6033.

Hye Jung Han, Karl B. Sebby, David J. Singel, and Mary J. Cloninger. "EPR Characterization of Heterogeneously Functionalized Dendrimers" Macromolecules 2007, 40, 3030-3033.

Lynn E. Samuelson, Karl B. Sebby, Eric D. Walter, David J. Singel and Mary J. Cloninger. "EPR and affinity studies of mannose-TEMPO functionalized PAMAM dendrimers." Org. Biomol. Chem. 2004, 2, 2075-3079.

Robert J. Usselman, M. T. Klem, M. Allen, Eric D. Walter, K. Gilmore, T. Douglas, M. Young, Y. Idzerda, and D. J. Singel. "Electron magnetic resonance of iron oxide nanoparticles mineralized in protein cages." Journal of Applied Physics 97, 10M523 s2005d.

Eric D. Walter, Karl B. Sebby, Robert J. Usselman, David J. Singel, and Mary J. Cloninger. "Characterization of Heterogeneously Functionalized Dendrimers by Mass Spectrometry and EPR Spectroscopy.” J. Phys. Chem. B 2005, 109, 21532-21538.

Eric K. Woller, Eric D. Walter, Joel R. Morgan, David J. Singel, and Mary J. Cloninger. "Altering the Strength of Lectin Binding Interactions and Controlling the Amount of Lectin Clustering Using Mannose/Hydroxyl-Functionalized Dendrimers.” J. AM. CHEM. SOC. 2003, 125, 8820-8826. 
An Artificial Neural Network Approach to Multiphase Continua Constitutive Modeling, Lucon, Peter A, and Donovan, Richard P. Composites Part B, 2007, 38, 817-823

Application and Testing of a Cougaar Agent-Based Architecture, Mike Emery, John Paxton, Richard P. Donovan. Proceedings of the Fourth IASTED International Conference on Computational Intelligence, Calgary, Alberta, Canada. July 4-6, 2005

Vehicle Identification Smart Sensor Web: An AI Approach to Screening for Intent, Donovan, Richard P, Wirth Aaron, Overcast, Desiree. Proceedings of the 2007 IEEE Conference on Technologies for Homeland Security.

"Reconciling Lithopheric Deformation and Lower Crustal Flow beneath Central Tibet" R. Bendick (UM/M) and L. Flesch. Geology, v.35, p.895 (2007)

"Berkeleydione and Berkeleytrione, New Bioactive Metabolites from an Acid Mine Organism" Donald B. Stierle, Andrea A. Stierle, J. David Hobbs, and Jon Clardył, Organic Letters, Vol.6, No. 6, 1049- 1052 (2004).

"Water Evaporation", Science Mine article, Montana Standard, (2004) J. D. Hobbs

Dan Cleary and J. D. Hobbs. "Bioinformatics Tools and Methods with Cluster Computing" Montana Tech/NSF Undergraduate Research Presentation (2004).

Joseph Henrich and J. D. Hobbs. "Photo-Reduction, Attenuation, and Extraction of Metals in Mine Waste Waters". Montana Tech/NSF Undergraduate Research Presentation (2004).

A. A. Stierle, D. B. Stierle, J. D. Hobbs, G. Loewen, L. Christiaens, and J. Barlow. "Investigation of an Unusual Nonnucleosidal Reverse Transcriptase Inhibitor from a Symbiotic Bacterium of a Marine Sponge" (2007) in preparation

"Modeling the Growth and Assembly of Calcium Phosphate Nanoparticles on Bio-Polymer Backbones" NSF-EPSCoR UGRP, submitted 2008

"Utilization of Cluster Computing to Increase Performance of Seismic Data Processing Software" NSF-EPSCoR UGRP, submitted 2008

MC Machczynski, KP Kuhl, and MA McGuirl. "Modulation of the Electrochemical Behavior of Tyrosyl Radicals by the Electrode Surface." Anal. Biochem 362:89-94 (2007).

B. J. Keller, S. K. Hurst, E. S. Peterson, L. H. Spangler and E. H. Abbott. "Solution Equilibria Leading to the Formation Metal-metal Bonds in Partially Oxidized Bisoxaltoplatinate(II) Systems." Inor. Chim. Acta. Vol (2004) 357/3 853-858.

S. K. Hurst, L. Spangler, E. H. Abbott, R. Larsen and E. S. Peterson. "Preparation and Properties of Partially Oxidized N-methylisoquinolinium Bis(oxalato)platinate Nanowires." Inor.Chim. Acta.(2004)1 358 173-176. 
D. Sartori, S. K. Hurst, N. Wood, R. Larsen, and E. H. Abbott. "Crystal structure, physical properties and Pt-195 NMR characterization of Pt(bipy)Br2." Chemical Crystallography (2005) 35995.

P. J. Martellaro, S.K. Hurst, R. Larson, E.H. Abbott, and E.S. Peterson. "Multifnuclear Nuclear Magnetic Resonance and X-ray Crystallographic Investigation of Some Mixed Ligand Alkylisocyanide Platinum(II) Complexes.” Inorg. Chim. Acta. 358 (2005) 3377-83.

B.M Anderson, S.K. Hurst, L. Spangler, E.H. Abbott, P. Martellaro, P.J. Pinhero, and E.S. Peterson. "The Investigation of the Macroscopic and Nanoscopic Physical Properties of the Partially Oxidized Polymers of Bisoxalatoplatinum(II) and Tetracyanoplatinum(II)." J. Matl. Sci. (2006).

\section{People Who Worked on the Project}

This project was worked on by:

13 Ph.D's

4.2 Postdocs

9 Graduate students

10 Undergraduate students

2 M.S.'s

1 Tenured faculty member

1 Research scientist

All participants received partial support, which is clearly detailed on the Financial Statement. Generally, all faculty received 1-2 months of support, usually as summer salary. The program management provided 1-2 months of support to the coordinator and 0.25 FTE to the computer specialist who also maintained the DOE DEARS database. Most undergraduate students received salary for up to $19 \mathrm{hrs}$ per week during the academic year, full time in the summers. Most to the graduate students and post-docs received partial support from DOE and the associated match funds.

\section{Other Support}

\section{Rosenburg}

New funding during the last 1.5 years:

Immobilized Metal Polyamine Composites (IMPACS) for Removal and Recovery of Negatively Charged Species from Contaminated waters and Mine Leaches," Edward Rosenberg, Montana Board of Research and Commercialization Technology (MBRCT), \#7-03, July 1, 2006-June 30, 2008, \$217,459. 
"Structural Design at the Polymer-Surface Interface with Nanoporous Silica Polyamine Composites," Edward Rosenberg, National Science Foundation, 0709738, August 15, 2007- July 31, 2010, \$360,000.

"Visiting Faculty Award, for Dr Carlo Nervi, ”Edward Rosenberg, University of Montana, January-July, 2007, \$1,500.

Grants as Co-Principal Investigator/Co-Project Director

"STTR Phase I Arsenic and Selenium Remediation with Immobilized Metal Polyamine Composites," Edward Rosenberg and Carolyn Hart (Purity Systems Inc), National Science Foundation, 0610506, July 1, 2006-June 30, 2007, \$100,000 (\$48,635 to UM)

Note: A Phase II grant cannot be submitted because the company is now less than $51 \%$ US citizen owned

\section{Schmidt}

V. Hugo Schmidt's current support is from DOE under subcontract DE-AC06-76RL01839 from Battelle Memorial Institute and PNNL for solid oxide fuel cell work. His pending support is from the NASA EPSCoR program, also for solid oxide fuel cell work. Neither has overlap with the projects described in this final report.

\section{Abbott}

None

\section{Charles Spangler}

None

\section{David Dickensheets}

Project/proposal title: Endoscopic Doppler Optical Coherence Tomography for Gastrointestinal Imaging

Source of support: Canadian Institute of Health Research

Project location: University of Toronto / Montana State University

Total award amount: \$140,000 (MSU share of project)

Starting - Ending dates: 09/01/05 - 08/31/09

Support type: current

Person-months per year committed to the project: 1.0 calendar month

Overlap / Relationship to DOE Project: Employs MEMS mirrors developed with partial support from DOE project

Project/proposal title: Confocal Raman Spectroscopy and Imaging for Skin Cancer Detection

Source of support: NIH 
Project location: Vanderbilt University/ Montana State University

Total award amount: $\$ 688,000$ (MSU share of project)

Starting - Ending dates: 03/01/06 - 12/31/09

Support type: current

Person-months per year committed to the project: 2.0 calendar months

Overlap / Relationship to DOE Project: none

Project/proposal title: MRI: Acquisition of inductively coupled plasma etcher to support research and teaching in micro and nanodevices

Source of support: NSF

Project location: Montana State University

Total award amount: $\$ 300,000$

Starting - Ending dates: 08/01/07 - 07/31/10

Support type: current

Person-months per year committed to the project: 0 calendar month

Overlap / Relationship to DOE Project: Provides instrument for the MMF Cleanroom, which

DOE project also supported

Project/proposal title: IDBR: Agile electronic focus and aberration control for live animal

imaging

Source of support: NSF

Project location: Montana State University

Total award amount: \$ 391,156

Starting - Ending dates: 07/01/08 - 06/30/11

Support type: pending

Person-months per year committed to the project: 1.0 calendar month

Overlap / Relationship to DOE Project: Will advance MEMS mirrors developed with partial support from DOE project

Project/proposal title: STTR: Compact Aberration Compensated Focus and Scan Control for Biomedical Sensors

Source of support: NSF

Project location: Bridger Photonics

Total award amount: \$ 150,000

Starting - Ending dates: 07/01/08 - 06/30/09

Support type: pending

Person-months per year committed to the project: 1.0 calendar month

Overlap / Relationship to DOE Project: Will advance MEMS mirrors developed with partial support from DOE project

Project/proposal title: MEMS Variable Focus Lens: Technology Development for Commercial Applications in Medical Imaging and Consumer Electronics

Source of support: Montana Board for Research and Commercialization Technology

Project location: Montana State University

Total award amount: \$ 150,000

Starting - Ending dates: 07/01/08 - 12/31/09 
Support type: pending

Person-months per year committed to the project: 1.0 calendar month

Overlap / Relationship to DOE Project: Will advance MEMS mirrors developed with partial support from DOE project

\section{Lee Spangler}

Sponsoring Agency: DOE

Title: Basic Science of Retention Issues, Risk Assessment \& Measurement, Monitoring \& Verification for Geologic $\mathrm{CO} 2$ Sequestration

Total Award Amount: $\quad \$ 7,147,998 \quad$ Start and End Dates: 10/01/04 - 6/30/08

Additional Information: Project has 8 PIs, and includes a large subcontract $(\$ 2,250,000)$ to

another university, Spangler is Project Director

Status: Current Person-Months Committed: 2 months annually

Award \# DE-FC26-04NT42262

Sponsoring Agency: DOE EPSCoR Implementation Program

Title: Applications of Charge Transfer to Optical and Opto-Electronic Materials and Devices

Total Award Amount: $\quad \$ 4,800,000 \quad$ Start and End Dates: 01/1/04 - 12/31/06

Additional Information: Project has 8 PIs, Spangler's funding is $\sim \$ 50,000$ per year.

Status: $\quad$ Current $\quad$ Person-Months Committed: 1 month annually

Award \# PG-5230-01

Sponsoring Agency: NSF MRI Instrument Development

Title: Development of a Step-Scan Fourier Transform Spectrometer With sub 1/2 HeNe

Wavelength Step Size

Total Award Amount: $\quad \$ 320,527 \quad$ Start and End Dates: 08/01/03 - 07/31/07

Status: $\quad$ Current Person-Months Committed: 1 month annually

Award \# 0321258

Sponsoring Agency: DOE

Title: High Temperature Electrochemistry

Total Award Amount: $\quad \$ 9,253,415 \quad$ Start and End Dates: 06/01/02 - 9/31/07

Additional Information: Project has 9 PIs, and 48 total personnel. Spangler is Project Director

Status: $\quad$ Current Person-Months Committed: 2 months annually

Award \# DE-FC26-04NT42262

Sponsoring Agency: Concurrent Technologies Corporation

Title: Technology Development Issues For Power Generation From Montana Canola And Other Oil Seed Crops

Total Award Amount: $\quad \$ 675,000 \quad$ Start and End Dates: $10 / 01 / 04-09 / 30 / 07$

Additional Information: Spangler has a small project management role

Status: Current Person-Months Committed: 0.5 month annually

Award \# 040900113

Sponsoring Agency: Small Business Administration 
Title: Microdevice Fabrication Facility

Total Award Amount: $\quad \$ 1,987,000 \quad$ Start and End Dates: 08/15/03 - 08/14/08

Additional Information: Primarily a construction \& equipment acquisition project.

Status: Current Person-Months Committed: 0.25 month annually

Award \# SBAHQ-03-I-0046

Sponsoring Agency: NASA

Title: Microdevice Fabrication Facility

Total Award Amount: $\quad \$ 1,488,000 \quad$ Start and End Dates: 06/15/06 - 6/15/07

Additional Information: Primarily a construction \& equipment acquisition project.

Status: $\quad$ Current Person-Months Committed: 1 month annually

Award \# NNG06GJ18G

Sponsoring Agency: DOD subcontract through University of Montana

Title: Development of Laser Bee Sensor Using Wingbeat Modulation

Total Award Amount: $\quad \$ 564,409 \quad$ Start and End Dates: 07/07/05 - 09/22/06

Additional Information: 3 PIs

Status: $\quad$ Current $\quad$ Person-Months Committed: 1 month annually

Award \# PG-7809-02

Sponsoring Agency: Universal Technology Corporation

Title: High Power Density Solid Oxide Fuel Cells

Total Award Amount: \$186,321 Start and End Dates:

Additional Information:

Status: Current Person-Months Committed: 0.25 month annually

Sponsoring Agency: US Department of Energy

Title: Big Sky Regional Carbon Sequestration Partnership-Phase II

Total Award Amount: \$6,496,521 Budget Period 10/01/2005 - 03/31/2008

Start and End Dates: 10/01/2005 - 09/30/2009

Additional Information: Cooperative Agreement \# DE-FC26-05NT42587 Amendment \# A007

Status: Current Person-Months Committed:

Award \# DE-FC26-05NT42587

\section{Aleks Rebane}

Research Projects Ongoing or Completed the Last 3 Years

"Two-Photon Porphyrin Core Dendrimers for Optical Power Limiting"

PI: Aleksander Rebane, Montana State University.

Agency: AFOSR (DEPSCoR)

Award Period: 06/01/2005 - 06/01/2008 (ongoing)

This project is devoted to finding organic porphyrin-based materials for optical power limiting applications. 
"Image-Guided Photodynamic Therapy to Sanitize Breast Cancer Draining Lymph Nodes," P.I. Aleksander Rebane/Jean Starkey

Agency: Montana Board for Research and Commercialization Technology

Award Period: 08/01/2007 - 09/31/2008 (ongoing)

This project is to develop a new deep tissue penetrating tumor imaging and cancer treatment modality that would greatly reduce the incidence of lymphedema The imaging is based on emerging hyper-spectral imaging technology, and will allow imaging the lymphatic system including lymph nodes at appreciable tissue depth. The treatment of cancer will utilize a new type of deep tissue penetrating two-photon assisted photodynamic therapy technology developed at Montana State University.

\section{David Singel}

NIH 5 yr.

$\$ 510,000$

Structural Characterization of Prion Isoforms in Multiple TSE Diseases

With Michele McGuirl U. Montana, awarded.

Major goal is to elucidate the structure of the prion [protein ( $\mathrm{PrP})$ in

its aggregated isoforms, through advanced and high-frequency EPR

spectroscopy.

NIH COBRE (DJS component) 3 yr. \$300,000

Center for Analysis of Cell Signaling

Ed Dratz, PI, pending. Project: Proteomic Profiling of Candida albicans

Responses to Nitrosative and Oxidative Stress

The major goals of this project are: to elucidate the countermeasures

taken by C. Albicans in response to redox stress by mass

spectrometric/proteomic measurements of post-translational modifications

of protein thiols; to predict pathways of redox stress responses by

integrating the proteomics results in systems models; and to test the

pathways through analysis of the comparative responses of homo- and

heterozygous knockout strains vs. wild-type C. albicans.

\section{Michele McGuirl}

NSF 0346069

$$
5 / 01 / 04-4 / 31 / 09
$$

MA McGuirl

Annual Direct Cost $\$ 77,250$

CAREER: Understanding the role of amino acid radicals in electron transfer Despite the significance of amino acid radicals in biology, their electrochemical and ET properties are not well defined. The goal is to directly measure these properties using the $\beta$-sheet protein azurin and the 4-helix bundle protein cytochrome c' as model systems.I 
Grant \# 08-48 Montana Board of Research and Commercialization Technology (MBRCT) G Gillispie Fluorescence Innovations, Inc (PI)

$$
\text { 7/31/07-6/30/09 }
$$

Annual Direct Cost $\$ 30,000$ (McGuirl portion)

Collaborative Research Applications of Innovative Protein Fluorescence Lifetime Spectrometer. The goal of this sub-project is to develop a drug screening assay for treating/preventing prion disease specifically for the FI2 company's instrument, which measures the fluorescence lifetime of tryptophan.

NIH 1R01GM081649-01A1

MA McGuirl

$$
4 / 01 / 08-3 / 31 / 13
$$

Annual Direct Cost \$195,953

Structural Characterization of Prion Isoforms in Multiple TSE Diseases The major goals of this project are to determine the structures of prion fibrils using SDSL EPR and chemical crosslinking, in wild type and diseased mutants of prion protein.

\section{Cost Status}

The total approved budget was $\$ 1,022,302$. Cost sharing, breakout by DOE share, recipient share and total costs are clearly detailed in the Financials Statement.

A brief summary appears below. Actual cost incurred are reported in the Financial Statement to the Chicago Office.

\section{Fiscal Year}

\begin{tabular}{|c|c|c|c|c|c|}
\hline \multicolumn{6}{|l|}{ Calendar Year } \\
\hline 2004 & $\begin{array}{l}2005 \\
\$\end{array}$ & 2006 & 2007 & 2008 & Total \\
\hline $\begin{array}{l}\$ 195,650.16 \\
\text { (Actual Figure }\end{array}$ & $\begin{array}{l}276,306.77 \\
\text { s) }\end{array}$ & $\$ 274,446.47$ & $\$ 187,942.83$ & $\$ 27,527.85$ & $\$ 961,874.08$ \\
\hline \multicolumn{6}{|l|}{ Total } \\
\hline Budget & $\begin{array}{l}\$ 1,022,302.00 \\
\$\end{array}$ & & & & \\
\hline Spent & $(961,874.08)$ & & & & \\
\hline Balance & $\begin{array}{l}\$ \\
60,427.92\end{array}$ & & & & \\
\hline
\end{tabular}

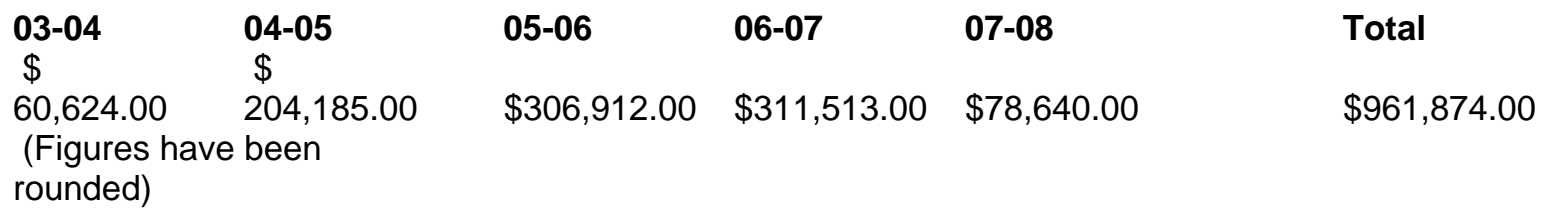

